\title{
URBAN STAGE TRANSCRIPT: MAPPING PERFORMANCE SPACES IN A HERITAGE URBAN PARCEL
}

\author{
KARTINI KASMURI, NUR ATIQAH HUSAINI \& FAIRUZ REZA RAZALI \\ Centre of Studies for Architecture, Faculty of Architecture, Planning and Surveying, \\ Universiti Teknologi MARA, Malaysia
}

\begin{abstract}
Performance and performativity are inherent to urban life and design. The idea of a city as "theatre of social action" according to Lewis Mumford has been contextualized through the roles of theatre and performance in urban life. The notion of theatre and performance here is more than metaphoric. In a parcel of Georgetown, Penang, the urban fabric provides historical spatial background as urban scenography; while in another sense, providing imagination of a performance through individuals' routine that embodies the community's collective values, desires, memories and aspirations. The deeprooted existence of performing arts and cultural expression is now ploughed by the diminishing community that contributed to this scenario. This paper attempts to formulate strategies and tools of an urban catalyst that will revive the parcel into an area robust with business, religious and cultural activities that it once was. The potential of the site lies within its heritage cultural practices, heavily signified by its long-standing history of performance and artistic expressions in the urban parcel, which is now a host for the Penang Philharmonic Orchestra. Historical settings function as new imaginative performance spaces for citizens who assume the colliding and interchanging roles of both the performer and the audience. The new series of urban scenography become various nodes throughout the parcel, accommodating diverse typologies of "urban stage" and "micro theatres". Subsequently, connectivity among these nodes is traversed by a network of "corridors". As such, this plexus of urban performance ultimately encourages a certain level of culturally charged resiliency and rebrands the parcel as a sustainable entity thriving on creative economy. This formula aims to be a catalyst to a chain of reaction in rejuvenating George Town through new programs of cultural contextualisation.

Keywords: performance, routine, nodes, urban stage, micro theatre, urban scenography.
\end{abstract}

\section{INTRODUCTION}

George Town is the capital of Penang, situated on the island north-west of Peninsular Malaysia. With a long history from being a Malay fishing village to being one of the most important site of British colony to becoming a free state following the formation of Malaysia in 1963 [1], George Town has enjoyed economic growth due to its status as a port town and strategic location on the straits of Malacca. The town has received many migrants from China and India prior to World War I and since then became a successful trading post. These migrants would later create their own distinct settlements in the shop houses built by the British colony. Their culture and beliefs that would later assimilate into the local norms of George Town birthing its utter uniqueness [1], marking an important shift in the ethnic fabric of George Town and resulted in a revolution of the built environment. The migrants from China were mostly traders and have taken up the lifestyle of having both functions of a house and commerce under one roof-the shophouse [2]. The hybridity of building usage eventually impacted the urban environment by creating intensity and diversity that delineates a successful urban setting [5].

As a UNESCO World Heritage site, George Towns tourism economy sees an expansion of the city itself [1]. However, the subsequent lifestyle change due to economic pressures and vast technology has led to the disappearance of the traditional shophouse lifestyle. The 
majority of shop houses are either overtaken by mundane generic commercial image or turned into offices. It is no longer the bustling urban centre, filled with diverse individualities that are unique to George Town. Gentrification slowly cripples the nostalgic liveliness and romance of the city with its crumbling rows of shophouses [7]. Ambitions of the younger generation, too, could not be contained in the narrow shophouses anymore. The fear of the shophouses becoming irrelevant in comparison to the ultra-modern developments in cities such as Kuala Lumpur may materialise if action to rejuvenate the city is not taken.

\subsection{Site setting}

The study is focused on a parcel (Fig. 1(b)) in the main masterplan of George Town (Fig. 1(a)), which was built on the original grid formed during the British colonial era. The internal road network marks its boundaries.

The parcel (Fig. 1(b)) in the early days is known as the Chinese enclave where Chinese settlers set up shop and live above the stores. Their presence is further solidified by the existence of one of the oldest temples in Penang, Kuan Yin Temple, abutting the parcel. In the heart of the study area also sits the infamous King Street Temples that have become a tourist attraction due to its richness in religious and cultural activities; occasionally a public affair. Following this, part of the road network becomes the main festival route for festivities such as the Chinese New Year parade, the Hungry Ghost festivities and Tua Pek Kong festivities [14]. The highlights of these festivities are often the cultural performances such as the lion dance, Chinese puppet shows and opera stage. While the performance settings are scattered all along the festival routes, the main stage would always be on Lebuh Queen, with the signature shop houses as key urban scenography. Such idea of mapping traditional urban performance is adopted in the proposed Urban Transcript strategy.

Present-day gentrification has mostly eclipsed over the image and important roles that these historical shophouses had in their urban setting. With businesses either closing down or moving elsewhere, many storefronts and building frontages became dysfunctional and fail to attract users. The natural routine of the place is being broken by diverting urban dwellers to busier streets with more surveillance and security. Consequently, the habitable portion of these shophouses became vacant. As a result, the area became inferior due to lack of intensity, except during peak hours of the day or at times of festivities. This results in an unsafe public realm, especially at night.

Over the years, Penang Heritage Trust (PHT) and Think City has taken a step towards reinventing the parcel. One such effort is the building called The Star, Pitt Street.


Figure 1: (a) The boundary of proposed master plan and (b) the studied parcel. 
The refurbishment of the 3-storey historical building houses The Star's island office, the Think City office and an office for Penang Philharmonic Orchestra with several medium sized rehearsal spaces [15]. It also offers a book shop on the ground floor and several rentable spaces for private functions. As a continuation of such functional reinterpretation of the parcel in revolutionising George Town's masterplan, this study expands on the idea of cultural intervention as a potential urban catalyst to revive its robustness through cultural, business and religious activities.

The specified guidelines for developing George Town has set some constraints in terms of zoning and preservation, where four development categories are identified (Fig. 2) [7]:

- Category I: Historically significant buildings that must not be changed at any cost

- Category II: Historical shop houses where the façade must be maintained

- Infill: Vacant lots or buildings that are built with respect to the surrounding architecture

- Replacement: Buildings built without the consideration of the surrounding architectural context.

Only buildings in category II, Infill and Replacement may be reinvented with new programs. Within the parcel, $72 \%$ of the buildings are shophouses of category II, Infill and Replacement while only $20 \%$ are category I buildings, mainly comprising Chinese temples and kongsi - providing a lot of opportunity for physical intervention.

The opportunities and strengths in performance spaces have been identified as four site potential factors: permeability, nodes, building frontages and performance spaces (Figs 3-6).
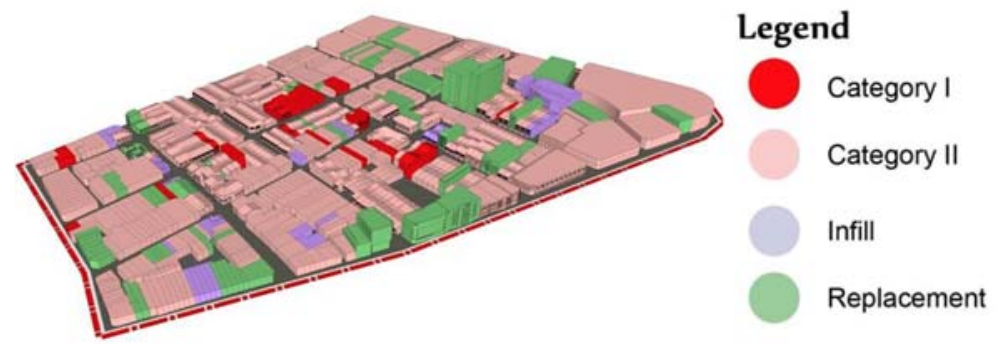

Figure 2: Building categories as stipulated in the George Town Development Guideline.

\subsection{Site potentials}

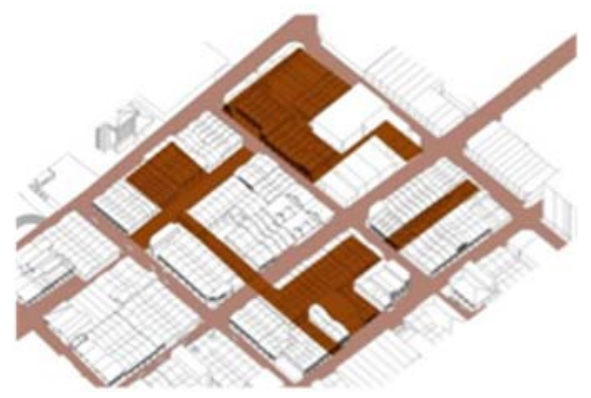

Figure 3: Potential open new connections + public ground floor (permeability). 


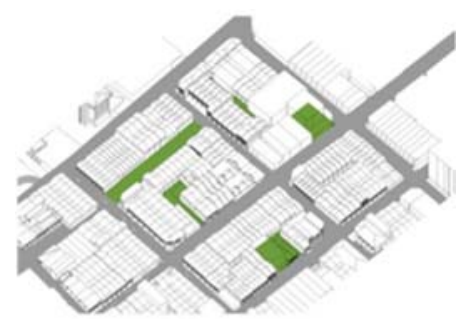

Figure 4: Potential open public space (nodes)

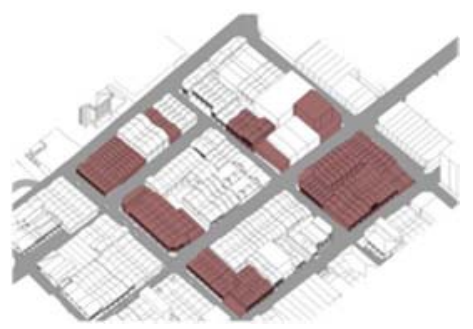

Figure 5: Potential mixed-use shop houses (building frontages).

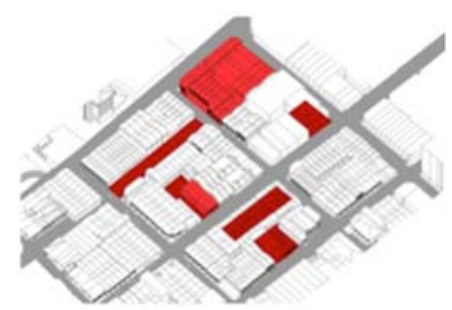

Figure 6: Potential performance spaces ("urban stage").

\section{DESIGN THEORY AND CONCEPT}

2.1 The parcel: a cultural quarter in a fine grain urban setting

Referencing "small is beautiful", a term coined by Leopold Kohr, an economist, further refined by Madeleine Bunting, used to champion small, appropriate technologies that are believed to empower people [3]. The idea is to reinvent the historically small and narrow shop houses of George Town to be people-centred and having a more intimate approach that creates focus on human relationships. The aim is to achieve a "fine grain" urban setting that coincides with the size and emphasise the romanticism George Town is known for.

The idea of fine grain according to Jane Jacobs' Death and Life of Great American Cities is to achieve the essence of urban life that lies in exuberant diversity. An urban quarter that consists of primary programs supported with secondary programs allows different types of people to utilize the area for different purposes at different times of day; thus increasing concentration of people on the street and in turn creates intensity in the quarter [4]. She further 
elaborates on the need for permeability and places connected through streets with spaces for people watching are key to a successful urban quarter [4].

The notion of fine grain achieved through horizontal and vertical grain is discussed in Howard Davis' book Living Over the Store: Architecture and Local Urban Life. The discussion of historical shop house setting with the multifunctional spaces has dated back several centuries with families having businesses on the ground floor and living quarters on the first [5]. This form of hybridity is the continuum that allows multi-functional spaces and flexible arrangement of shop house usage. It creates a dynamic architectural relationships between dwelling and the shop [5].

The theory of urban regeneration through cultural quarters was proposed by John Montgomery with a formula of cultural production and consumption into mixed use development and reconfiguration of public realm [6], creating a sense of place with respect to the historical and cultural values in establishing relationships between building and spaces. This theory was applied in the successful rejuvenation of Temple Bar in Dublin, Ireland where active frontages became the primary tool to create an active street life. An introduction of site-specific cultural activities, mixed use programs and flexible spaces were key [10] in establishing new and robust routines, which creates a balanced interaction between the place and the people.

\subsection{Choices and responses}

A responsive urban environment [11] is essentially democratic and enriches the opportunities for the people by maximizing the degree of choice available to them. As the main medium connecting the values of people-place interaction, claiming their rights to the city. Focusing on the qualities of permeability, variety and robustness [11], this theory is adopted to support the notion to centralize the idea of performativity in the parcel to create a paradigm shift towards a sustainable and robust urban setting through an array of urban stage typologies resulting from the proposed formulation.

\subsection{Performing the city}

George Town is to be rebranded as a patron to the city's urban theatre incorporating stages and scenography that illuminates the culture, religion and routine of the citizen. The idea of "a city as a theatre", championed by Lewis Mumford, revolves around experiencing the urban environment and selling the idea of an economy based on this experience [8]. This concept highlights the essence of a city lies in the "urban scene" and "urban drama" in the sense of physical spaces, architecture and the design of cities; comprising a multitude of performative qualities such as tension and irony. The "urban drama" is the routine act of the citizens practicing their everyday life through performing their collective memory, imagination and aspiration [8].

His writing also contemplates on the question of identity-formation through this urban performativity [8]. It suggests that the act of formal performances on actual stages with scripted scenes incorporated into the urban fabric may become a point from which the formation of identity ripples throughout the city. Another element that must be taken into consideration is that the people eventually becomes both the spectator and coperformer whereby their interaction with the performances, public spaces and infrastructure is a process of self-identification; of performing the self.

Bernard Tschumi's study of urban performativity through The Manhattan Transcript [9] explores confrontation among use, form and social values. It delineates that space, movement 
and events are independent but produce new relations when its components are broken down and rebuilt along different axes. The urban fabric is broken down into the infamous tripartite mode of notation introduced by Tschumi, the "events, movements and spaces" to discover the order of experience, moments, intervals and sequences when reading a city [9] - a plot. The study unearths layers of creation of spaces - scenes - through events and movements that occur in a plot, whereby these scenes are mapped out in different axes in order to experience the same plot differently.

\subsection{Reconfiguring the parcel}

Stemming from this concept, Saki Ichikawa [12] explored the idea of urban public theatre for street culture through contextualism, where London is reconfigured in the context of experience from the perspectives of three protagonists - the visitor, the performer and the observer'. The tourist, as a visitor, has viewpoints of the city; the performer senses the city as a theatre and the stage set designer (an observer) investigates the quality of space; street theatre [12]. It is concluded that public spaces assumes diverse qualities and functions as they become street theatres; a space to rest or gather as an auditorium; and at the same time, potentially accommodates a stage and sometimes stage set, thus giving urban performativity its literal function. In the context of a large city, these micro theatrical spaces can be interconnected, thus creating a macro theatre module across the city. Consequently, the macro theatre network may expand into larger applications in cities throughout the state. As complexity increases, this hierarchical growth would presumably be adaptable into extensive environments through a "super lobby/corridor" [13].

These theories gave birth to the idea of re-inventing the parcel through performance spaces - formal and informal - and mapping the spaces in the public realm and the built environment. The performativity and connectivity must tie strongly to the culture, religion and routine of the people in the area.

\subsection{Urban scenography}

In urban performativity, physical entities such as architecture and infrastructure make up the urban scenography [17] where buildings become the setting against which the performers (i.e. city dwellers) act. The occupation of formal and informal performing spaces encourages spontaneous public gatherings and street theatre events [17] and functions as a platform for natural formation of relationship among the audience, the performer and the space occur.

George Town houses an eclectic variety of buildings with different typologies, architectural styles and at varying scales - for example, Colonial style offices, Chineseinfluenced shophouses, Indian-influenced mosques. Inherently, these different types of building frontage embody varying urban scenographies for different typologies of "urban stage"; assuming the role of "backdrop" or environmental setting for confrontations among the key elements of urban performance: Performer, Audience, Space. It is the dynamism and local relevance of these settings that are translated into the different typologies of urban stage in the transcript.

\section{URBAN STAGE TRANSCRIPT}

The conception of reinventing the parcel driven by "urban drama" must be set off by highlighting potential nodes. These nodes were studied based on The Manhattan Transcripts idea and concluded in a recurring urban model (Fig. 7). The recurring urban model was analysed into several floating typologies of combinations of "stage" and "audience" (Fig. 8). 
These typologies would then be applied into the nodes or micro theatres, creating spaces for events and movements as well as events and movements for spaces (Fig. 9). In order for the spaces to contain or spill out the events and movements, multifunctionality must be incorporated.

The events, movements and spaces create a map of the performance spaces and directing the individuals through these spaces experiencing both the role of a performer and the audience. This map is the transcript for the parcel in response to the idea of performativity in the urban setting.

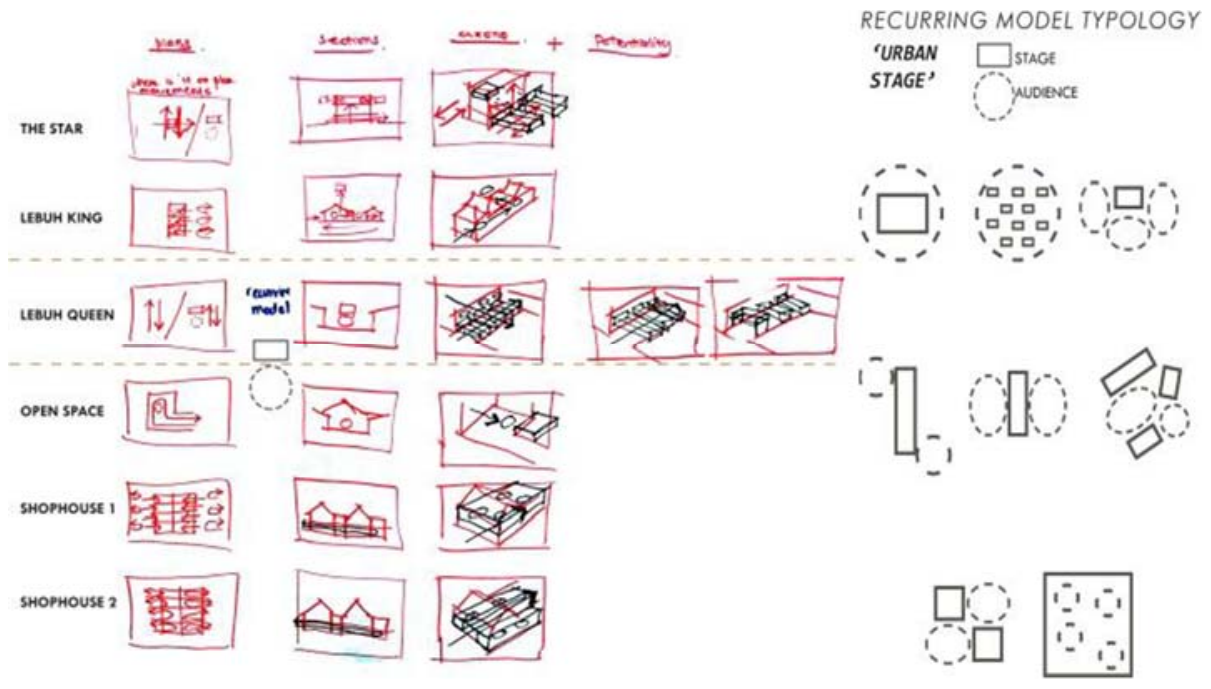

Figure 7: Analysis of nodes and the recurring models of "stage+audience" typology.



Figure 8: Floating typologies to be incorporated into the parcel from the recurring model. 


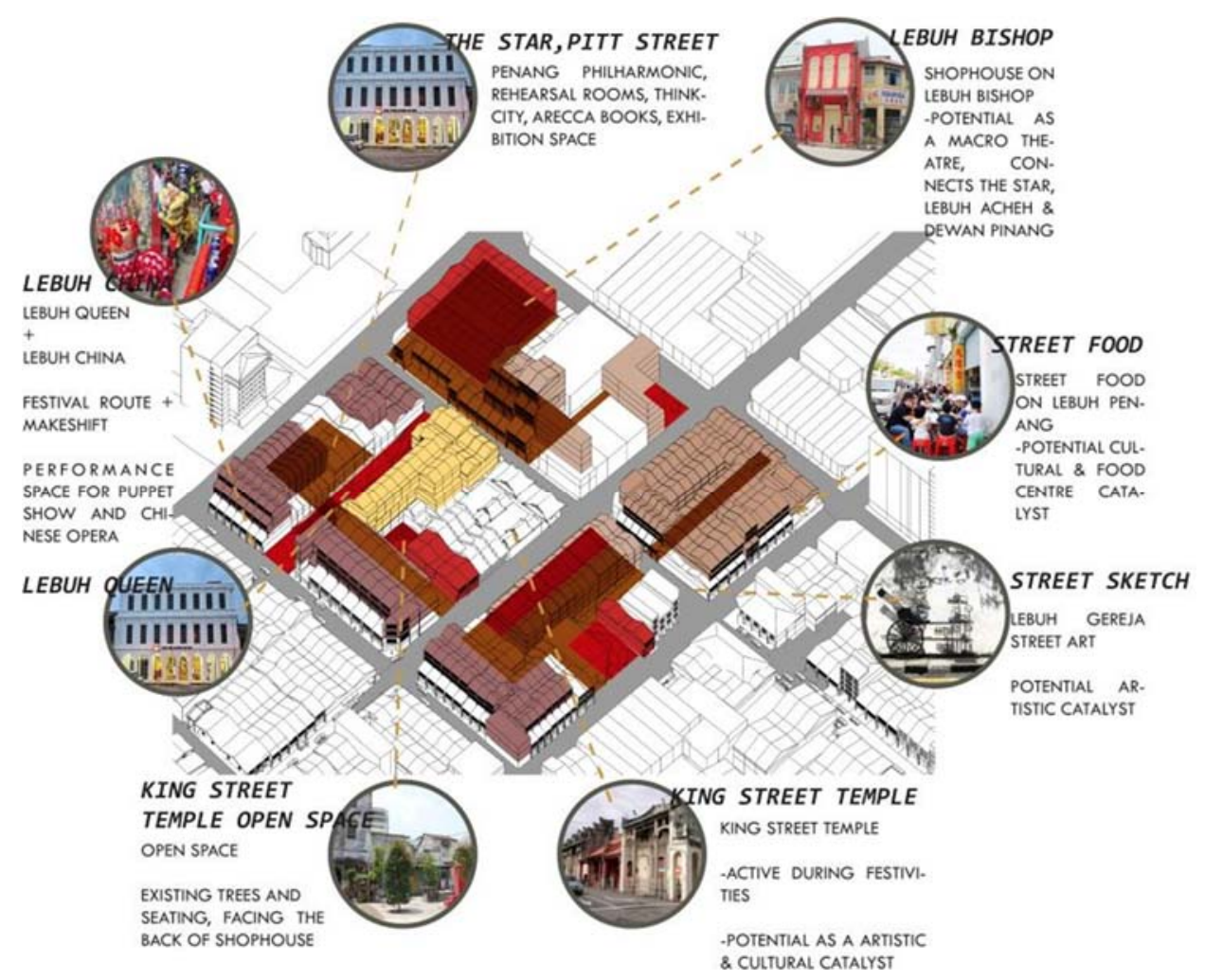

Figure 9: Nodes to be incorporated with the "stage + audience" typologies.

\subsection{Mapping the urban performance space}

The strategies of the "urban stage" include physical, social and economic instruments. However, in this study, only the physical and social instruments will be elaborated. The physical instrument: hybrid re-organisation of programs in the built environment and public spaces. To promote diversity and resilience, this includes creating active storefronts [4], allocating public realms on ground floor and introducing vertical diversity. Secondary or supporting programs to the urban performances are then introduced to create robustness.

The next set of urban tools work hand in hand; namely the "creative cultural catalyst" and the "new connectivity". These tools are key framework in the mapping of the performance spaces. The creative cultural catalyst is extracted from the site study, whereby the potential of the site lies in its history of performativity. These elements will be connected by a new form of connectivity that utilizes existing streets, back lanes and ground floor of shophouses. This connectivity will be set off on an axis separate from the norm of the site but finds new relationships that complement the cultural and historical values of the parcel.

The social instrument aims on "engaging creative community" and to "enliven socioeconomy". Such community shall become patrons to the idea of formal and informal urban performance; comprising young professionals and tourists as "tenants" in the parcel. 


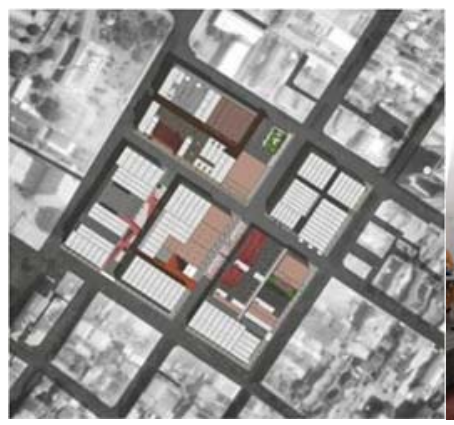

(a)

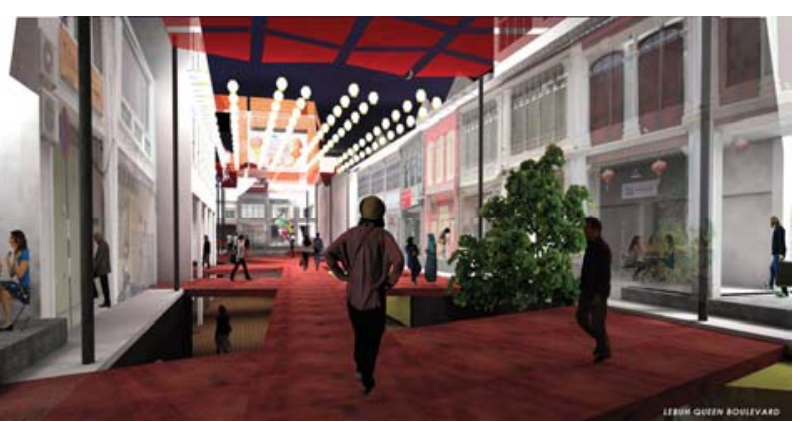

(b)

Figure 10: (a) Ground floor site plan incorporating the "Macrotheatre", "Super-village" and "Super-corridor"; (b) Multi-level ground surfaces on Lebuh Queen.

These strategies culminate into the formation of three main interventions: "Macrotheatre", "Super-village" and "Super-corridors". The conception of these ideas are based on the study of theories on urban regeneration and performing the city (Fig. 10(a)). The "Macrotheatre" is a collective of nodes or micro theatres identified on site with potential of becoming multifunctional performance spaces. These nodes are the main element of the map, inter-connected by a series of linkages inclusively known as the "Super-corridors" which also functions as a canvas for street cultures of public art; subsequently a public realm. The idea of "Supervillage" will be the collective outcome of the diverse reorganisation of mixed use programs in the built environment and the reinvention of the public realm (Fig. 10(b)).

\subsubsection{Typologies}

These site-specific typologies (Figs 11-13) are created from the analysed floating typologies incorporated on site with respect to the urban fabric, culture and values. The accumulation of all these typologies ties the parcel together in creating an urban stage transcript that may become a model to shift the paradigm of the whole site to become reinvented as a performative parcel of George Town's urban fabric.

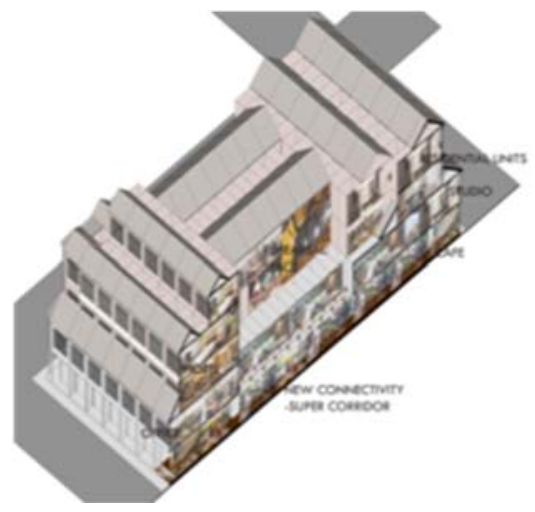

Figure 11: Super-village model in a block of existing shop house. 


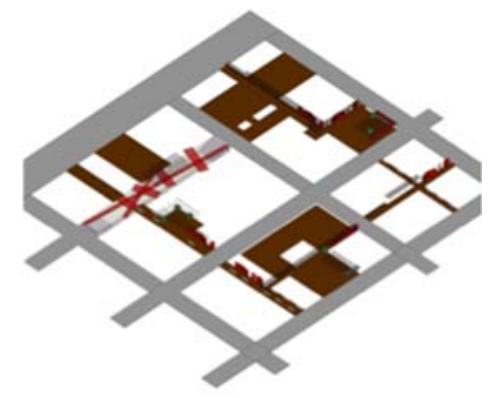

Figure 12: Super-corridor that connects the performance spaces.
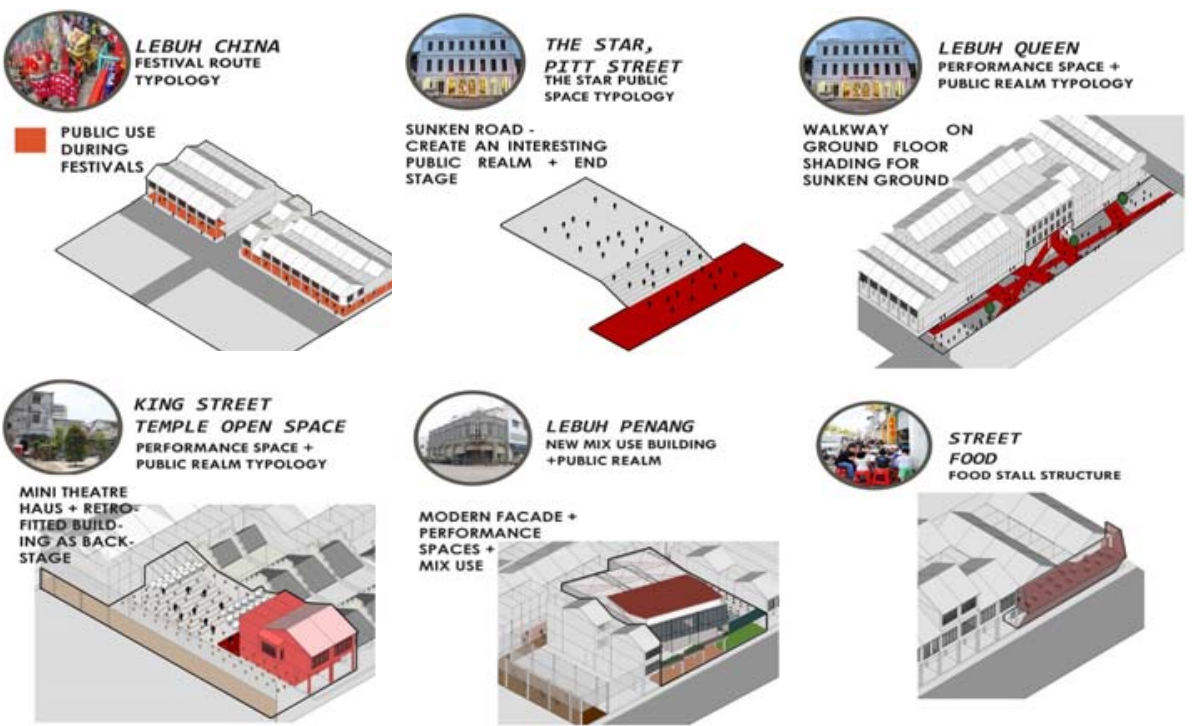

MODERN FACADE
PERFORMANCE
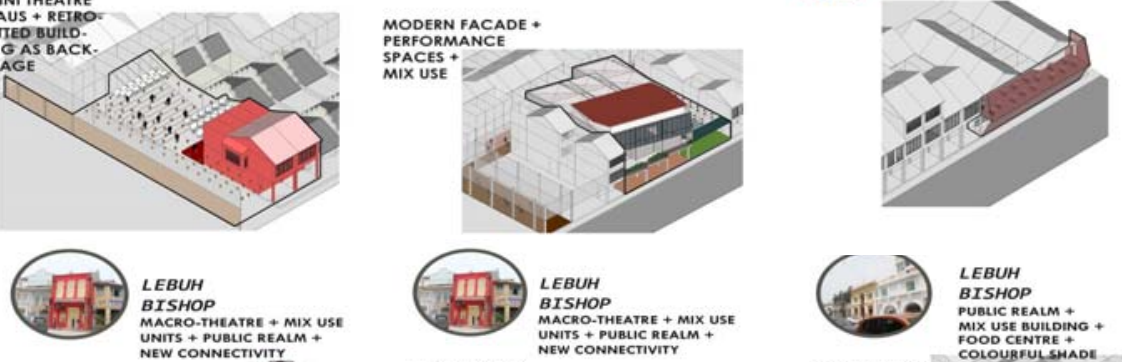

LEBUH

BTSHOP
MACRO-THEATRE + MIX USE MACRO-THEATRE + MIX US
UNITS + PUBLIC REALM +

MAIN THEATRE
-ICONIC SKIN
PLEATED SKIN UNITS + PUBLC REALM PLEATED SKIN
WITH ANIMA. IION OF SHOW
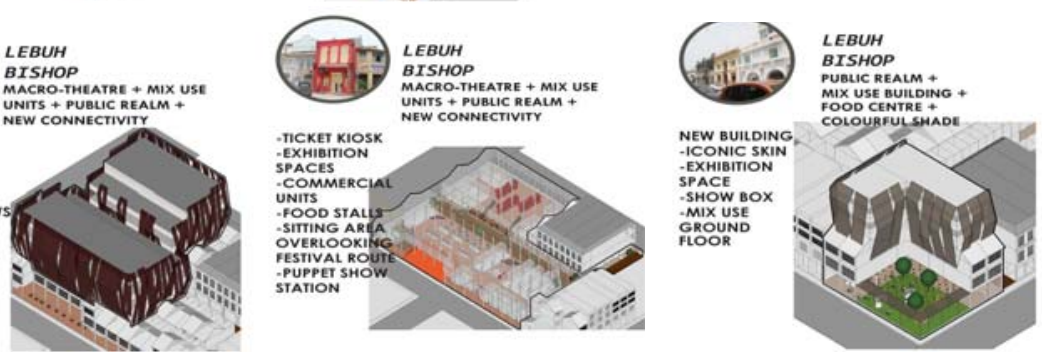

Figure 13: Typologies of urban performance spaces and multi-functional performance space creating the "Macrotheatre".

\section{CONCLUSION}

The Urban Stage Transcript embodies the trail of urban performance at various scales, creating layers of events that occur in hierarchical sequences. The connectivity among 
different typologies and locality of the "urban stages" are as important as the programs being injected into these flexible spaces. It is also interesting to see how different building frontages, as urban scenography, provide unique possibilities of manipulation in reaction to movement (routine) being performed in the space (public realm)-establishing dynamic relationships between people and place. Integrating physical, social and economic actors, this model of urban intervention seeks to develop a culture-driven creative economy for George Town.

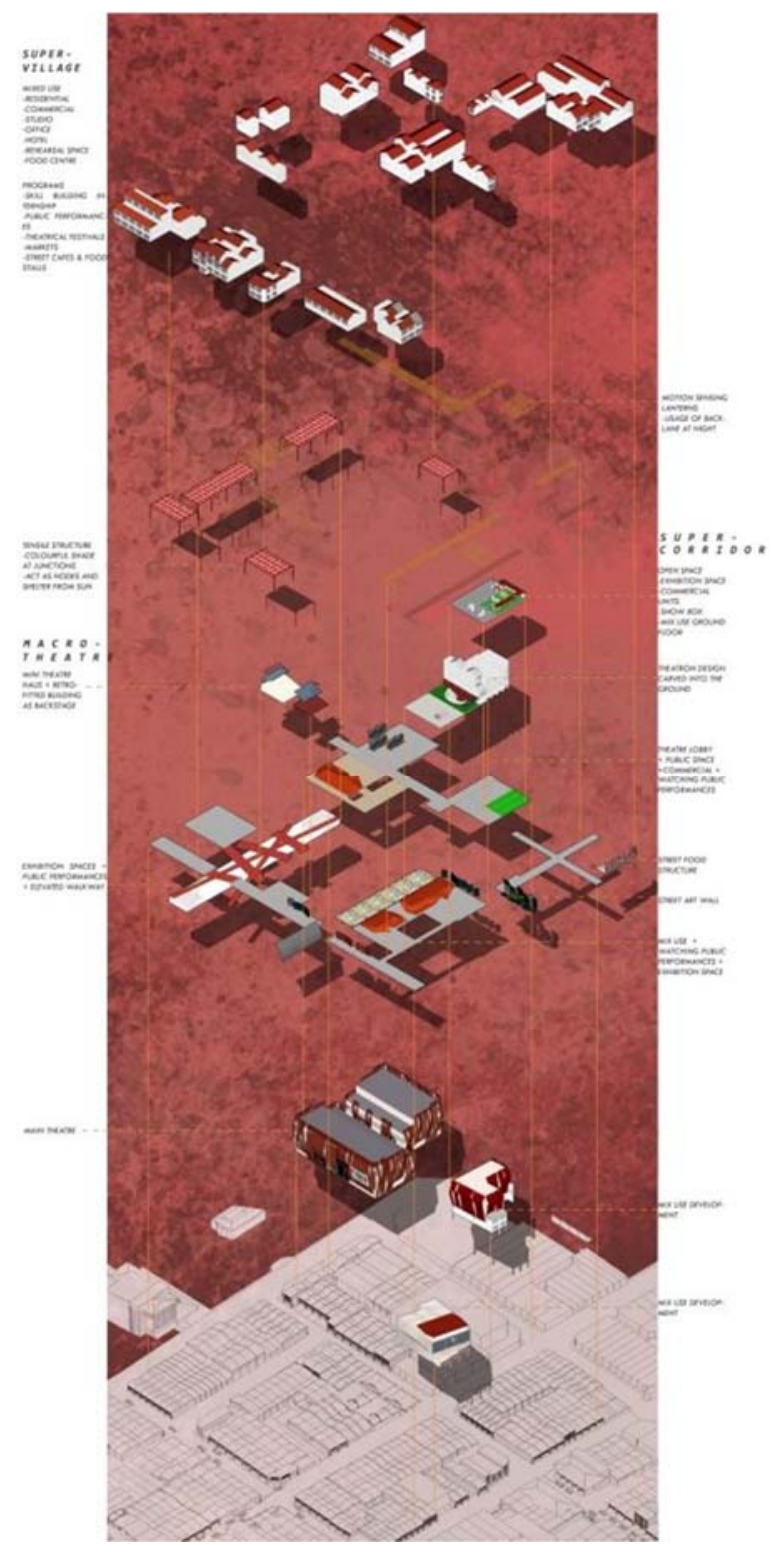

Figure 14: Overall scheme of the "Urban Stage Trasncript" as depicted in an exploded axonometry. 


\section{REFERENCES}

[1] Suet, L. K., Narimah, S., Nurwati, B. \& Sharifah, R.S.D., The Promise and Perils of the Island City of George Town (Penang) as a Creative City, Urban Island Studies, $\mathbf{1}$, pp. 20-34, 2015.

[2] Wang, H. \& Jia, B., A Morphological study of traditional shophouse in China and Southeast Asia, Green Architecture for Sustainable Living and Environment. Procedia - Social and Behavioral Sciences, 179, pp. 237-249, 2015.

[3] Bunting, M., Small is Beautiful - An Economic Idea That Has Sadly Been Forgotten, an article posted on The Guardian, 10 Nov. 2011, www.theguardian.com/ commentisfree/2011/nov/10/small-is-beautiful-economic-idea.

[4] Broadbent, G., Emerging Concepts in Urban Space Design, New York: Van Nostrand Reinhold (International), 1990.

[5] Davis, H., Living Over the Store: Architecture and Local Urban Life, London and New York, NY: Routledge, pp. 15-20, pp. 89-141, 2012.

[6] Montgomery, J., Cultural Quarters as Mechanisms for Urban Regeneration.Part 1: Conceptualising Cultural Quarters, Planning, Practice \& Research, 18(4), pp. 293306, November 2003.

[7] George Town, Historic Cities of The Straits of Malacca, Special Area Plan, Majlis Bandaraya Pulau Pinang, George Town World Heritage Inc., 2013.

[8] Makeham, P., Performing the City, Theatre Research International, 30(2), pp. 150160, International Federation for Theatre Research, 2005.

[9] Tschumi, B., The Manhattan Transcripts: Theoretical Projects, London: Academy Editions, pp. 13-44, 1994.

[10] Montgomery, J., Cultural Quarters, Examples and Success Factors: A Review of Temple Bar, Dublin, Urban Cultures Ltd, www.portphillip.vic.gov.au/

[11] Bentley, I., Alcock, A., Murrain, P., McGlynn, S. \& Smith, G., Responsive environments: A Manual for Designer, London: Architectural Press, 1985.

[12] Ichikawa, S., Urban Public Theatre, Architectural Association School of Architecture, Projects review 2011, projectsreview2011.aaschool.ac.uk/students/saki-ichikawa.

[13] Gupta, N., The Hague: A Post-Civic City, Architectural Association School of Architecture, Dissertation Proposal for Architectural Association Projective Cities Programme, 2014.

[14] Stephen, E., Thai Pak Koong Temple, Penang: Presentation,

[15] http://issuu.com/ednerpatrickstephen/docs/thai pak kong temple presentation.

[16] Loh, A., The Star Pitt St, a building with a past and a future, an article posted on The Star, 4 Sep. 2014, www.thestar.com.my/lifestyle/features/2014/09/04/the-star-pitt-sta-building-with-a-past-and-future/.

[17] Howard, P., What is Scenography? (Excerpt), London, Routledge (2001), extract from City as Narrative in Introducing the New Midway: A Study in Urban Scenography, by Nuria Montblanch, 2006 http://www.nuriamontblanch.com/Urban-Scenography. 